\title{
Ultra-Sensitive Detection of Protein Thermal Unfolding and Refolding Using Near-Zone Microwaves
}

\author{
Kimberly M. Taylor, Student Member, IEEE, and Daniel W. van der Weide, Member, IEEE
}

\begin{abstract}
We use planar slot antennas proximal to proteins in solution to detect changes in conformation. The antennas are attached to fused-quartz or glass sample holders and the cuvette/antenna assembly is placed in the sample holder of an optical spectrophotomer (either UV/VIS or fluorescence polarization), allowing simultaneous dielectric and optical measurements. Return loss is recorded using a vector network analyzer. This system was used to study the equilibrium thermal unfolding and refolding of a small globular protein, as well as the binding of small hormones to a receptor. Good agreement between optical and microwave measurements was obtained for all systems studied. We show that microwave measurements can be made at protein concentrations as low as $0.3 \mathrm{ng} / \mathrm{mL}(19 \mathrm{pM})$, several orders of magnitude lower than that required for optical spectroscopy. The results from these experiments demonstrate that resonant slot antennas can be used to detect changes in protein conformation and the presence of microwave radiation does not perturb the system under study.
\end{abstract}

Index Terms-Biomedical applications of electromagnetic radiation, biophysics, proteins, slot antennas.

\section{INTRODUCTION}

D IELECTRIC spectroscopy is used to investigate gases, liquids, and solids in the radio, microwave, and terahertz frequency regimes (approximately $10^{6}-10^{15} \mathrm{~Hz}$ ). The technique has been successfully applied to biological specimens using various methods of application including time-domain reflectometry [2], [3], transmission lines [4], coaxial probes [5], and microfabricated waveguides [6]. While these studies have yielded potentially useful results, many of them suffer from one or more of the following disadvantages.

1) Experiments are performed on dry, but "hydrated" samples [3], [7], yielding results that may not be applicable to biomolecules in solution.

2) Results are qualitative rather than quantitative, i.e., a phenomenon is demonstrated, but its extent is not, or cannot, be further quantified [4].

3) Results are qualitative, but are not correlated with previously published results obtained with other techniques [8], [9].

Manuscript received April 21, 2004; revised October 31, 2004. This work was supported by the Army Research Office under Grant DAAD19-02-1-0081 and by the Office of Naval Research. The work of K. M. Taylor was supported by the National Institutes of Health under a Molecular Biophysics Training Grant.

The authors are with the the Department of Electrical and Computer Engineering, University of Wisconsin-Madison, Madison, WI 53706 USA (e-mail: ktaylor@cae.wisc.edu; danvdw@engr.wisc.edu).

Digital Object Identifier 10.1109/TMTT.2005.847047
We introduce a new application of dielectric spectroscopy in which proteins or other biomolecules are studied in an aqueous environment and in which optical spectroscopy is simultaneously performed [10]. This method not only allows measurement of proteins and other biomolecules in their "natural" aqueous state, but also permits correlation and comparison with results obtained using an established spectroscopic method. Variations of this technique have been previously described in the literature [11]-[13].

The phenomenon measured by dielectric spectroscopy is the polarization relaxation (also called dispersion) of one or more dielectric species. For biological samples, these relaxations are generally divided into three regimes. The $\beta$-dispersion is a broad rotational orientation of either the entire macromolecule or of specific groups (e.g., protein sidechains with a high degree of freedom may undergo their own dispersion) [14]. The frequency of the $\beta$-dispersion is inversely proportional to molecular size, and this type of dispersion generally occurs below $100 \mathrm{MHz}$. The $\gamma$-dispersion is caused by absorption of bulk water, and is generally seen as a wide peak with a maximum around $19.4 \mathrm{GHz}$ for pure water at room temperature [15], [16]. Water is strongly dielectric, and $\gamma$-dispersion is generally the largest dispersion observed in the radio, microwave, and terahertz regimes. The $\delta$-dispersion is located between the $\beta$ - and $\gamma$-dispersions, in the high radio to low microwave region (approximately $500 \mathrm{MHz}-20 \mathrm{GHz}$ ), and is largely caused by reorganization of "bound" water molecules near the surface of the protein or macromolecule [15]. These "bound" waters undergo dispersion at a lower frequency because they are rotationally and translationally hindered, and possess higher and more ordered dipole moments compared with bulk solution [17]. By addressing an appropriate frequency range in which $\delta$-dispersion is large while the contribution from $\gamma$-dispersion is strong but static, the dispersion of bound water can be used as a reporter for protein conformational change. The bound water shells are modified in response to changes in the conformation of a biological macromolecule such as folding or unfolding, association, and ligand binding. This concept has been used by other researchers: Denisov and Halle used water ${ }^{17} \mathrm{O}$ and ${ }^{2} \mathrm{H}$ magnetic resonance dispersion to examine the thermal denaturation of bovine pancreatic ribonuclease (RNase A) and other proteins [18].

In order to exploit $\delta$-dispersion, we chose to examine a frequency range between $3-20 \mathrm{GHz}$, and used planar slot antennas driven by a $50-\Omega$ coaxial cable. Planar slot antennas are commonly used at microwave frequencies [19], and consist of a rect- 
angular window cut into the ground plane of a metal-clad dielectric material. Slot antennas can be treated as $\lambda / 2$ devices, where the longest dimension of the slot is equal to approximately half of the principal resonant wavelength [19]. However, the impedance of the slot in this fundamental mode is very high [20], and a lower impedance (resulting in a better match to the coaxial feed) may be obtained by using the second mode, in which the slot length is equal to a full wavelength. The slot antenna is attached to a fused quartz cuvette (for simultaneous measurements in the range of $190-820 \mathrm{~mm}$ ) or to the sample holder of a fluorescence polarimeter.

We chose thermal denaturation of bovine pancreatic ribonuclease (RNase A) as a test system for very large conformational changes. Unfolding of a protein from its native to its denatured state is the largest conformational change a protein experiences under equilibrium conditions and, therefore, should be easily detected using the slot antenna system. RNase A is a highly stable 13.7-kDa globular protein that undergoes reversible two-state unfolding over a wide range of conditions [21], [22]. Three series of experiments were performed. In the first, unfolding and refolding of RNase A was performed over a range of $\mathrm{pH}$ from 2.5 to 5.0. In the second series, the sensitivity of the slot antenna system was investigated by performing unfolding/refolding of RNase A over concentrations from $0.26 \mathrm{ng} / \mathrm{mL}$ to $9.3 \mathrm{mg} / \mathrm{mL}$ (19 $\mathrm{pM}$ to $680 \mu \mathrm{M})$. Finally, the effects of microwave power on the unfolding of RNase A were explored by varying the power delivered by the network analyzer from -35 to $+5 \mathrm{dBm}$ (from $18 \mu \mathrm{W}$ to $1.78 \mathrm{~mW}$ ).

A scaled version of the planar slot antenna resonant in the 10-20-GHz range was used to perform simultaneous dielectric and fluorescence polarization measurements on the binding of hormones to human estrogen receptor $\beta$. Fluorescence polarization (FP) is a technique that exploits differences in the tumbling rate of fluorescently labeled ligands to detect binding events [23]. The protein human recombinant estrogen receptor- $\beta$ (ER- $\beta$ ) [24] was titrated with aliquots of fluormone $\mathrm{ES} 2$, a fluorescently labeled estradiol, in order to probe the thermodynamics of binding and obtain a dissociation constant $\left(K_{D}\right)$. This titration was repeated with unlabeled estradiol. The binding of unlabeled estradiol was monitored using microwave measurements only since neither estradiol, nor ER- $\beta$ responds fluorescently. Previous measurements of ER- $\beta$ /estradiol binding could only be performed using radiolabeled ligand [25].

\section{Methods AND Materials}

\section{A. Protein Preparation and Experimental Conditions}

RNase A (Type XII-A) was obtained in lyophilized form from the Sigma Chemical Company, St. Louis, MO, and was used without further purification. All protein solutions were dialyzed exhaustively before use. For concentrations above $1 \mu \mathrm{M}$, protein concentration was determined from the absorbance at $278 \mathrm{~nm}$, using an extinction coefficient of $0.72 \mathrm{mg}^{-1} \mathrm{~mL} \mathrm{~cm}^{-1}$ [21]. At lower concentrations, a modified Lowry assay [26] (Pierce Chemical, Rockford, IL) was used to determine concentration. Buffer conditions were: 1) 50-mM sodium acetate/acetic acid, $100-\mathrm{mM} \mathrm{NaCl}$ for $\mathrm{pH} 4-5$ and 2) 50-mM glycine/HCl, 100-mM

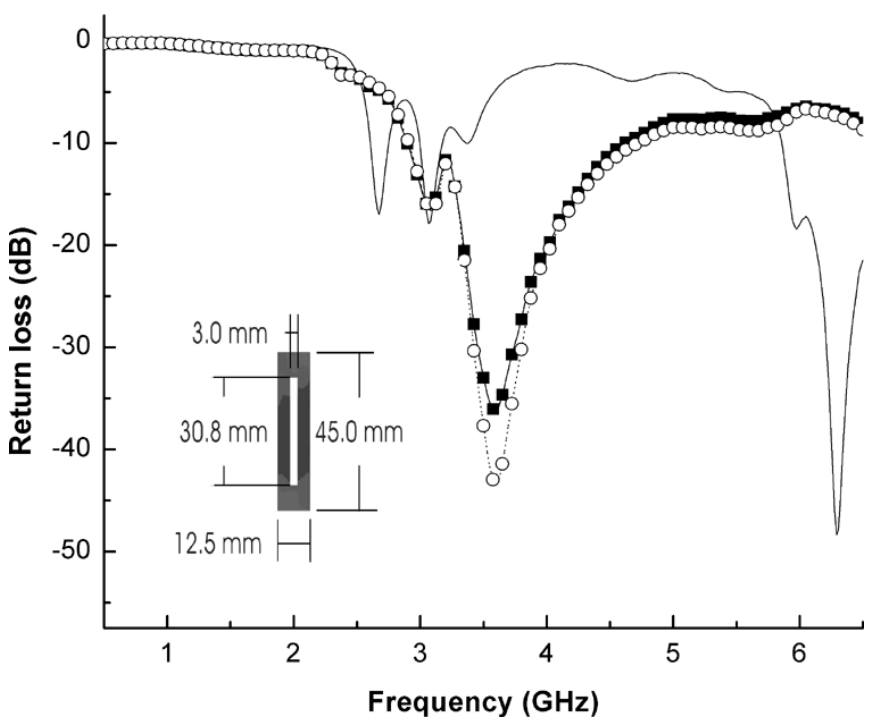

Fig. 1. Return loss of antenna/cuvette assembly employed for simultaneous UV/VIS and microwave recordings recorded at room temperature. Solid line is empty (air-filled) cuvette. Solid symbol (ם) is buffer at pH 4.5; open symbol (O) is $5.5 \mathrm{mg} / \mathrm{mL}(0.40 \mathrm{mM}) \mathrm{RNase} \mathrm{A}$ in the same buffer. Inset: dimensions of slot antenna.

$\mathrm{NaCl}$ for $\mathrm{pH} 3.5$ and below. The heat capacity $\Delta C_{p}$ of RNase A was treated as a constant $1.15 \mathrm{kcal} \mathrm{mol}^{-1} \mathrm{~K}^{-1}$ for all calculations [21].

Human recombinant estrogen receptor $\beta$, fluormone ES2 (a fluorescently labeled estradiol), and $17 \beta$-estradiol were obtained from PanVera, a division of Invitrogen, Carlsbad, CA. Buffer conditions were 100-mM potassium phosphate, $100-\mu \mathrm{g} / \mathrm{mL}$ bovine $\gamma$-globulin, $0.02 \% \mathrm{NaN}_{3}, \mathrm{pH} 7.4$.

\section{B. Slot-Antenna Fabrication}

Slot antennas were fabricated using RO-4003C high-frequency laminate from Rogers Corporation, Rogers, CT. The board had permittivity of 3.38, height of $0.813 \mathrm{~mm}$, and was doubly clad with 1 oz of copper. Antennas were cut using either an LPKF ProtoMat (LPKF Laser and Electronics AG, Garbsen, Germany) or a TAIG MicroMill (TAIG Tools, Chandler, AZ). Copper cladding was removed from one face of the antenna after fabrication, and a semirigid coaxial cable was soldered across the center of the slot window. Antenna dimensions for the antenna used for simultaneous UV/VIS spectroscopy and dielectric measurements are shown in Fig. 1.

\section{Spectroscopy and Thermal Denaturation}

An HP 8452A diode-array spectrophotometer equipped with a water-jacketed cell holder (Agilent Technologies, Palo Alto, CA) was used for all UV/VIS spectroscopy measurements. UV-transparent fused-quartz cuvettes of $0.5-\mathrm{cm}$ pathlength were obtained from Hellma GmbH and Company, Müllheim, Germany. An RTE-111 circulating water bath (Thermo Neslab, Portsmouth, NH) was used for temperature control. Return loss from the slot antenna was recorded using an HP 8720ES vector network analyzer (VNA) (Agilent Technologies, Palo Alto, CA). Unless otherwise specified, network-analyzer output 
power was fixed at $+5 \mathrm{dBm}(1.78 \mathrm{~mW})$. The UV/VIS spectrophotometer, VNA, and water bath were controlled by a PC using LabView 6i software (National Instruments, Austin, TX).

All temperature scans were taken under the following conditions: from $20^{\circ} \mathrm{C}$ to $80^{\circ} \mathrm{C}$ and back in $2{ }^{\circ} \mathrm{C}$ intervals with a 5-min equilibration time at each temperature. UV/VIS absorbance was recorded at $288 \mathrm{~nm}$ [21]. A volume of 1.6-mL buffer or protein solution was used in all experiments. Generally, three complete cycles from $20^{\circ} \mathrm{C}$ to $80^{\circ} \mathrm{C}$ and back were taken for each protein or buffer sample; reported thermodynamic parameters are the average of parameters from each of these scans. Unfolding and refolding were more than $95 \%$ reversible.

Midpoint temperature $T_{m}$ and van't Hoff enthalpy $\Delta H_{v H}$ were obtained from unfolding or refolding scans using the method of Marky and Breslauer [27]. Assuming that the protein undergoes a reversible two-state transition from native $(N)$ to unfolded $(U)$ states, the equilibrium constant $K$ can be defined as

$$
\begin{aligned}
N & \stackrel{K}{\rightleftarrows} U \\
K & =\frac{[U]}{[N]} \\
& =\frac{1-f}{f} \\
& =\exp \left[-\frac{\Delta H_{v H}}{R}\left(\frac{1}{T_{m}}-\frac{1}{T}\right)\right] .
\end{aligned}
$$

Here, $f$ is the fraction of protein in the native state, $R$ is the gas constant, $T$ is the temperature (in degrees Kelvin), and $T_{m}$ is the midpoint temperature (defined as the temperature at which $f$ is equal to 0.50 and $K$ is equal to 1 ). The signal $\alpha$ ( $\alpha$ is any observable, in this case, either the UV/VIS absorbance or the peak frequency) was equal to

$$
\alpha=B_{N} \cdot f+B_{U} \cdot(1-f)
$$

where $B_{N}$ and $B_{U}$ are, respectively, the native and unfolded baselines, defined as linear functions of temperature. An alternative baseline-free approach [28] was also used in which

$$
\frac{d \alpha}{d T}=A T^{2} f(1-f) \text {. }
$$

Here, $A$ is a scaling factor. The two methods yielded near-identical thermodynamic parameters, but the baseline-free method gave better determination of the midpoint temperature $T_{m}$.

\section{FP and Ligand Binding}

A Beacon 2000 fluorescence polarization system (Invitrogen, Carlsbad, CA) equipped with the standard spectrum range (360-700 nm) was used for all FP measurements. A small-scale slot antenna resonant in the range of $10-20 \mathrm{GHz}$ was attached to the Beacon's sample holder. The temperature of the sample was kept constant using the Beacon's built-in Peltier temperature control unit. Samples were contained in borosilicate glass $6 \times 50 \mathrm{~mm}$ test tubes (Fisher Scientific, Hampton, $\mathrm{NH}$ ), and sample volume was maintained at $500 \mu \mathrm{L}$ (for complete coverage of antenna). All instrumentation was computer controlled using the manufacturer's software for the Beacon system and LabView 6i for the VNA.
If the ligand is assumed to exist in only two states (bound to the receptor or free in solution), then an equilibrium exists between the free receptor, bound receptor, and complex such that

$$
\begin{aligned}
L+R & \rightleftharpoons L \cdot R \\
K_{D} & =\frac{[L][R]}{[L \cdot R]} .
\end{aligned}
$$

Here, $K_{D}$ is the dissociation constant [in units of moles/liter or molar (M)]. The anisotropy $A$ should be equal to

$$
\begin{aligned}
A & =f_{\text {bound }} A_{\text {bound }}+f_{\text {free }} A_{\text {free }} \\
& =f_{\text {bound }} A_{\text {bound }}+\left(1-f_{\text {bound }}\right) A_{\text {free }}
\end{aligned}
$$

where $f_{\text {bound }}$ and $f_{\text {free }}$ are the fractions of bound and free ligand, and $A_{\text {bound }}$ and $A_{\text {free }}$ are the anisotropy values for bound and free ligand. If $B$ is the concentration of the receptor-ligand complex, and $L_{T}$ and $R_{T}$ are, respectively, the total concentrations of ligand and receptor, then (4) can be rewritten as [29]

$$
\begin{aligned}
K_{D} & =\frac{\left[L_{T}-B\right]\left[R_{T}-B\right]}{B} \\
B & =\frac{\left(L_{T}+K_{D}+R_{T}\right)-\sqrt{\left(-L_{T}-K_{D}-R_{T}\right)^{2}-4 L_{T} R_{T}}}{2} \\
f_{\text {bound }} & =\frac{B}{L_{T}} .
\end{aligned}
$$

Data from either the Beacon instrument or the network analyzer were fit to (5) and (6) using nonlinear regression.

\section{RESULTS}

\section{A. Slot Antenna Design and Return-Loss Spectra}

The antenna dimensions were chosen to yield a principal resonance of approximately $3.5 \mathrm{GHz}$ when loaded with a cuvette filled with aqueous solution. Slot dimensions are shown in Fig. 1. Representative spectra of the empty (air-filled) cuvette and of the same cuvette filled with either buffer (50-mM sodium acetate/acetic acid, $100-\mathrm{mM} \mathrm{NaCl}, \mathrm{pH} 4.5$ ) or a solution of $0.40-\mathrm{mM}$ RNase A in the same buffer are shown in Fig. 1 The slot was expected to yield a single resonant peak, but multiple additional peaks are clearly present. In an ideal slot, the ground plane and dielectric substrate extend to infinity [30]. By contrast, the slot used in these experiments has a large slot and a relatively small ground plane. The unexpected resonances may also result from reflections from the cuvette and/or the cell holder.

The shape of the reflection return loss was invariant: a large peak at approximately $3.2-3.4 \mathrm{GHz}$ with multiple smaller side peaks. The return loss for buffer and RNase A are superficially similar, although the protein return loss was larger. We noted that any change in the cuvette/antenna assembly (including emptying or refilling of the cuvette) caused perturbation of the driving coaxial cable and, thus, changes in the return response. The return-loss pattern was very stable if the cuvette assembly was not disturbed.

Peak positions within the return-loss pattern were determined by the fitting to a series of Lorentzian peaks. In general, 7-11 
Lorentzian peaks were needed to obtain a good fit to the returnloss pattern.

\section{B. Antenna Response to Solute Titration}

As seen in Fig. 1, the return loss of a buffer solution differs from that of a solution of the same buffer containing $0.40-\mathrm{mM}$ RNase A. This dissimilarity is chiefly observed in the magnitude of the return-loss spectra, particularly at the major peak around $3.6 \mathrm{GHz}$.

Theoretically, the resonant frequency $f_{R}$ of the antenna should depend on permittivity $\varepsilon$ as $f_{R} \propto(1 / \sqrt{\varepsilon})$. Thus, a decrease in the permittivity is expected to increase the antenna's resonant frequency. The permittivity of a mixture of two dielectric materials can be approximated using a simplified form of the Wiener mixture equation [31]

$$
\varepsilon_{\mathrm{eff}} \leq v_{A} \varepsilon_{A}+v_{B} \varepsilon_{B}
$$

where $v_{A}$ and $v_{B}$ are the volume fraction of materials $A$ and $B$, and $\varepsilon_{A}$ and $\varepsilon_{B}$ are the permittivities of materials $A$ and $B$. It is assumed in (7) that the two materials are miscible, but do not interact. Equation (7) can also be expressed as

$$
\begin{aligned}
& \varepsilon_{\mathrm{eff}}=\varepsilon_{\mathrm{eff}}^{\prime}-j \varepsilon_{\mathrm{eff}}^{\prime \prime} \\
& \varepsilon_{\mathrm{eff}}^{\prime} \leq v_{A} \varepsilon_{A}^{\prime}+v_{B} \varepsilon_{B}^{\prime} .
\end{aligned}
$$

As a test for the sensitivity of the antenna resonance to permittivity changes, a solution of distilled deionized water was titrated with aliquots of low-permittivity solvent. Chosen for this experiment were methanol $\left(\varepsilon^{\prime} \approx 33.6\right.$ at $\left.25^{\circ} \mathrm{C}\right)$ and acetone $\left(\varepsilon^{\prime} \approx 20.7\right.$ at $\left.25{ }^{\circ} \mathrm{C}\right)$. The real portion of the permittivity of water at room temperature was taken as 80.4 at $20^{\circ} \mathrm{C}$.

The variation in peak position with permittivity for acetone and methanol is shown in Fig. 2. Data for both organic solvents vary in a similar manner with permittivity, and both fit well to an exponential model (not shown). Data at low organic volume fraction, or high permittivity, also fitted well to the inverse square root of the calculated permittivity $\varepsilon_{\text {eff }}^{\prime}$. Fits to the inverse square root formula were not possible for $\varepsilon^{\prime}$ below 60 , probably due to uncertainty in the volume of organic solute. Fits for this data are indicated in Fig. 2.

Titration of a buffer solution was also performed with two biological macromolecules: RNA (polycytidylic acid, or polyC) and the protein RNase A (shown in Fig. 3). Due to solubility concerns, concentrations of both macromolecules could not be measured above approximately $220 \mu \mathrm{M}$. Permittivity values for biological macromolecules vary, but many published accounts set $\varepsilon^{\prime}$ at only 2-4 for both RNA and protein [32]. Approximations such as in the derivation of (7) or (8) cannot be applied to aqueous solutions of most biological macromolecules because there are significant interactions between solvent water and the macromolecules. However, peak positions for both polyC and RNase A vary linearly with protein concentration over this limited concentration range. Thus, our technique is sensitive to the concentration of aqueous solutes, including biological macromolecules, in a linear fashion.

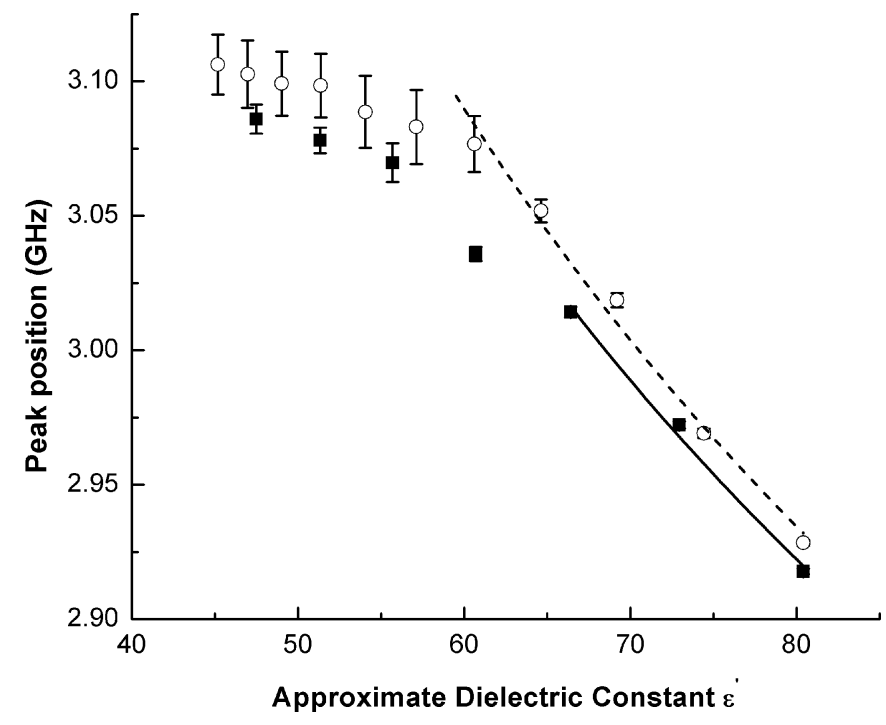

Fig. 2. Variation in peak position with approximately dielectric constant for acetone (closed symbols) and methanol (open symbols). Lines indicate fit to the inverse square root of the permittivity: acetone (solid line; $R^{2}=0.994$ ) and methanol (dashed line; $R^{2}=0.989$ ).

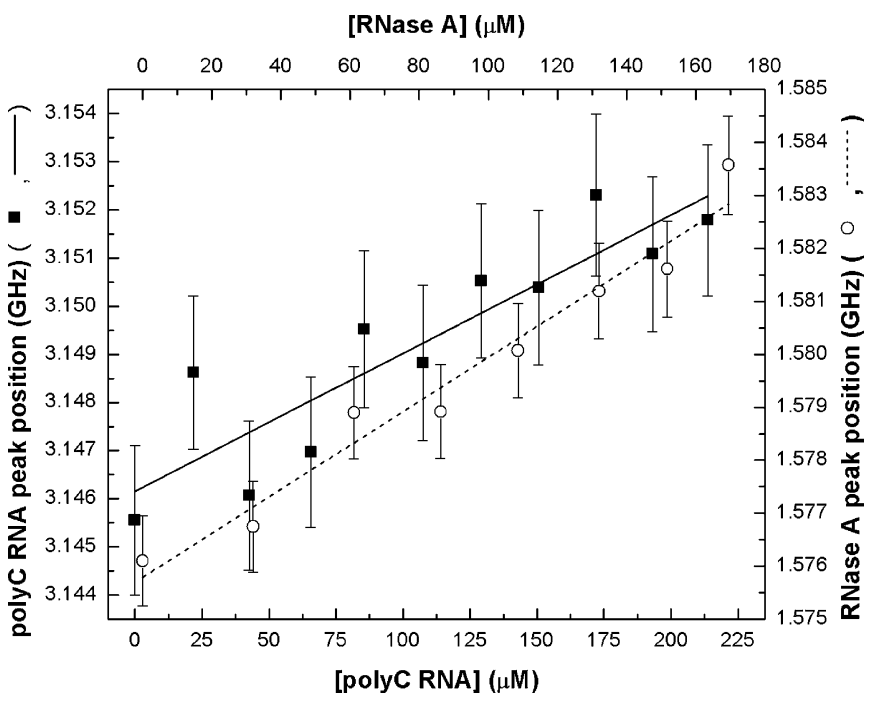

Fig. 3. Variation in peak position with concentration of the biological macromolecules RNA (polycytidylic acid, or polyC, closed symbols) and RNase A (open symbols). Peaks were derived from Lorentzian fit of the complete return-loss spectrum (data not shown). Lines are linear fits to: RNA (solid line; $R^{2}=0.803$ ) and RNase A (dashed line; $R^{2}=0.963$ ).

\section{Protein Unfolding and Refolding}

Although the buffer and RNase A return loss scans as described above were superficially similar, their temperature-dependent behaviors were quite different. Fig. 4 shows the behavior of RNase A return loss at selected temperatures between $20.43{ }^{\circ} \mathrm{C}-76.56^{\circ} \mathrm{C}$. The amplitude of the major resonant peak decreases with increasing temperature, and the position of this peak shifts to lower frequency. The center frequencies of all peaks were determined by fitting the return-loss scan at each temperature to a series of Lorentzian peaks (Fig. 5). A fixed number of peaks (7-11) were used to fit all return-loss scans in an unfolding/refolding series.

The behavior of individual peaks could be assessed by plotting peak position versus temperature. The behavior of a peak 


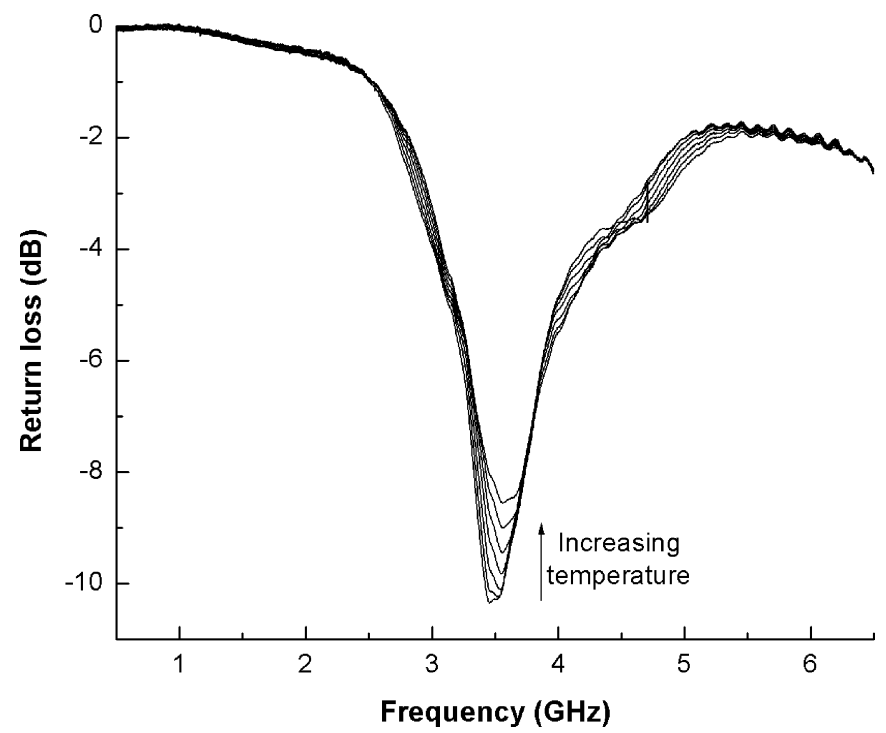

Fig. 4. Variation of return loss of $5.6 \mathrm{mg} / \mathrm{mL}(0.41 \mathrm{mM})$ RNase A at $\mathrm{pH} 4.5$ with temperature. From bottom to top, temperatures are $20.43{ }^{\circ} \mathrm{C}, 30.10^{\circ} \mathrm{C}$, $38.99^{\circ} \mathrm{C}, 48.72^{\circ} \mathrm{C}, 57.96^{\circ} \mathrm{C}, 67.28^{\circ} \mathrm{C}$, and $76.56^{\circ} \mathrm{C}$.

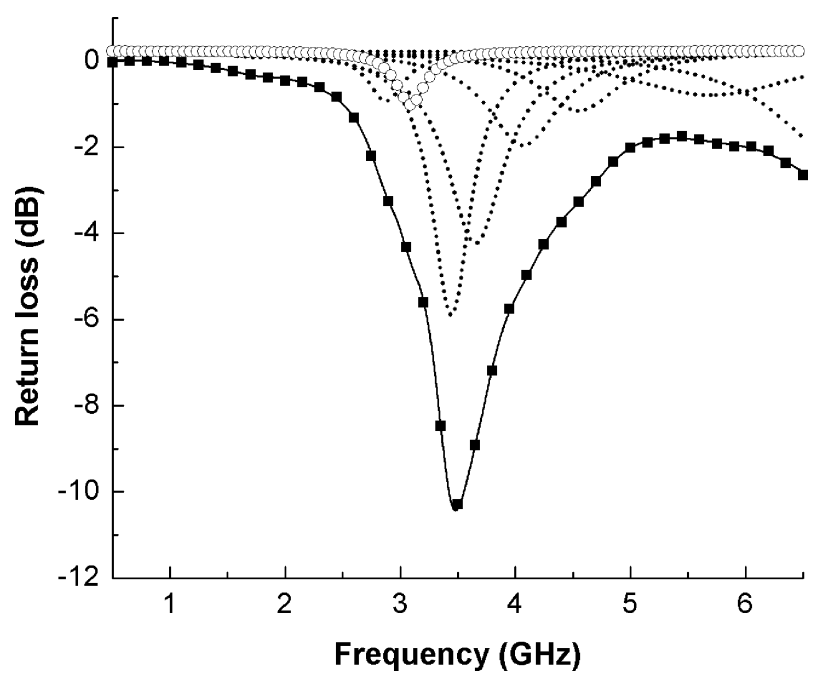

Fig. 5. Fitting of return loss of RNase A at $20.43{ }^{\circ} \mathrm{C}$ with nine Lorentzian peaks. This data is from the same experiment featured in Fig. 4. Solid symbols (ם) are raw data, the solid line is the fit. Dotted lines indicate individual Lorentzians; the peak at approximately $3.1 \mathrm{GHz}$ plotted in Fig. 6 is shown as open symbols $(\bigcirc)$.

at approximately $3.1 \mathrm{GHz}$ from the RNase A solution is shown in Fig. 6. The temperature-dependent variation of this peak frequency has a sigmoidal appearance characteristic of a cooperative phenomenon such as protein unfolding, and this data fitted well to a two-state unfolding model. After an initial increase in the peak position, the frequency of the corresponding peak from the buffer return loss scans decreased monotonically with increasing temperature, and could not be fit to a two-state model (data not shown). Fig. 6 also displays the fraction of protein in the native state derived from fits to the peak at approximately $3.1 \mathrm{GHz}$ from the network-analyzer data and to the UV/VIS absorbance at $288 \mathrm{~nm}$. Midpoint temperatures for the two data sets were similar $\left(59.18^{\circ} \mathrm{C}\right.$ for the network-analyzer data versus $62.46{ }^{\circ} \mathrm{C}$ for the UV/VIS data), as was unfolding enthalpy (59.2 and $63.7 \mathrm{kcal} / \mathrm{mol}$, respectively). This result demonstrates that

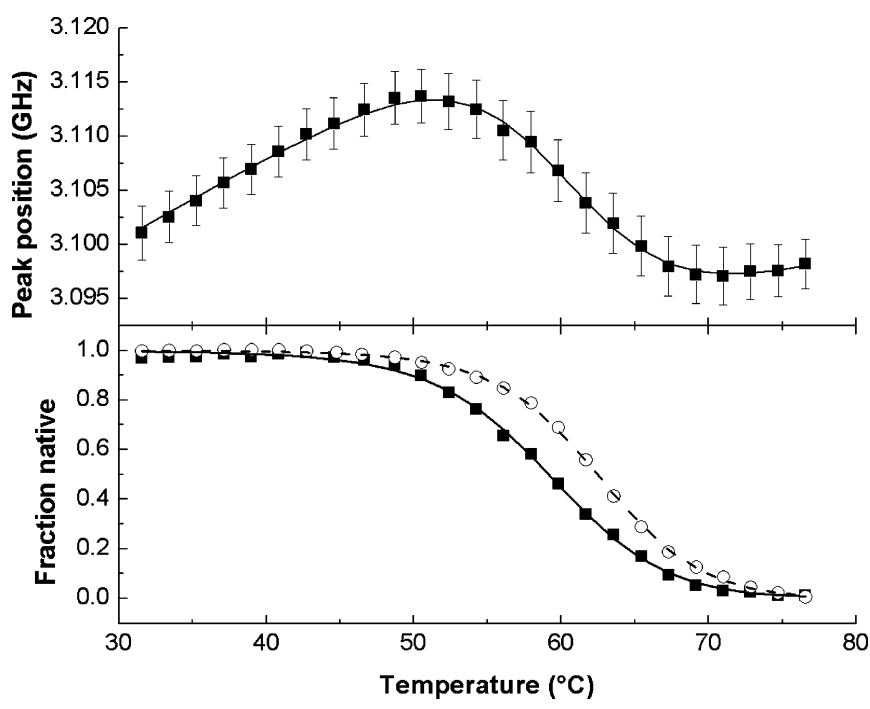

Fig. 6. Temperature-dependent behavior of a single peak (highlighted in Fig. 5) from Lorentzian analysis of return loss. Top panel shows variation of peak position with temperature (solid symbols) and fit to a two-state unfolding model (solid line). Bottom panel shows fraction native calculated from peak position (solid symbols and line) and from simultaneous UV/VIS absorbance (open symbols and dotted line).

the return loss data can be used to detect changes in protein conformational change.

Generally, one or more peaks from protein unfolding or refolding data fitted to a two-state model with similar midpoint temperature $T_{m}$ to that obtained from UV/VIS data. Due to variability of the return-loss pattern, peaks did always respond identically to protein conformational change. Values of $T_{m}$ reported are averages of all fits to peak position, and error in $T_{m}$ was often high due to variation in peak position fits. Determination of unfolding enthalpy $\Delta H_{v H}$ was more problematic. In most cases, reasonable values of enthalpy were obtained, as in the example above, but errors in enthalpy were very large, exceeding $20 \%$. Therefore, $\Delta H_{v H}$ will not be reported for the other experiments in this paper. These problems in midpoint temperature and enthalpy determinations, and possible solutions, will be revisited in the Section IV.

\section{D. $p H$ Series}

To ensure that the results obtained at $\mathrm{pH} 4.5$ were not an anomaly related to the behavior of the cuvette/assembly around $60{ }^{\circ} \mathrm{C}$, a series of unfolding/refolding assays at $\mathrm{pH}$ values between 2.5-5 were performed. Values of $T_{m}$ and $\Delta H_{v H}$ decrease with decreasing $\mathrm{pH}$ in this $\mathrm{pH}$ range as the protein stability diminishes with decreasing charge. At each $\mathrm{pH}$ value, two unfolding/refolding assays were performed, which are: 1) UV/VIS absorbance alone and 2) simultaneous UV/VIS absorbance and dielectric measurements. Values of midpoint temperature from these experiments are summarized in Table I. The $\mathrm{pH}$ series results from UV/VIS and network-analyzer peak fitting are summarized in Fig. 7. Also included in this figure are published midpoint temperatures obtained from differential scanning calorimetry [22].

Note that the error in $T_{m}$ derived from UV/VIS is assumed to be $0.50{ }^{\circ} \mathrm{C}$ based on estimates of the accuracy of the water bath 
TABLE I

VARIATION IN MIDPOINT TEMPERATURE WITH $\mathrm{pH}$

\begin{tabular}{lccc}
\hline \hline \multirow{2}{*}{$\mathrm{pH}$} & \multicolumn{3}{c}{ Midpoint temperature $\left({ }^{\circ} \mathrm{C}\right)$} \\
& UV/VIS alone & UV/VIS with & Return loss \\
\hline \hline 2.5 & $39.21 \pm 0.50$ & $39.21 \pm 0.50$ & $42.12 \pm 1.54$ \\
3.0 & $46.26 \pm 0.50$ & $46.77 \pm 0.50$ & $46.34 \pm 1.00$ \\
3.5 & $54.16 \pm 0.50$ & $54.01 \pm 0.50$ & $53.13 \pm 2.69$ \\
4.0 & $61.53 \pm 0.50$ & $62.01 \pm 0.50$ & $56.00 \pm 1.28$ \\
4.5 & $62.00 \pm 0.50$ & $63.56 \pm 0.50$ & $60.25 \pm 5.53$ \\
5.0 & $62.87 \pm 0.50$ & $63.00 \pm 0.50$ & $57.29 \pm 1.29$ \\
\hline \hline
\end{tabular}

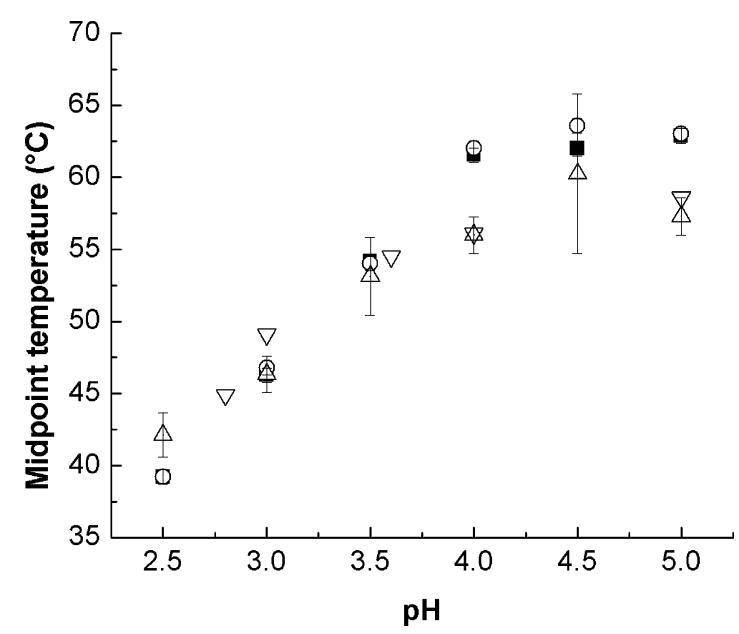

Fig. 7. $\mathrm{pH}$ dependence of midpoint temperature $T_{m}$ from UV/VIS absorbance recorded alone ( $\mathbf{\square})$, from UV/VIS absorbance recorded in the presence of microwave power $(\bigcirc)$, and from peak position analysis of return loss data $(\Delta)$. Also included are published midpoint temperatures derived from differential scanning calorimetry $(\nabla)[22]$.

and thermometer; fitting error in all cases is actually considerably lower. Reported error in the VNA $T_{m}$ is the standard deviation of the average of all midpoint temperatures determined from peak fitting.

Midpoint temperature recorded using UV/VIS absorbance in the presence of microwave power appears to be up to $1.6{ }^{\circ} \mathrm{C}$ greater than that obtained using the same method in the absence of microwave power. The average increase is $0.42{ }^{\circ} \mathrm{C}$, slightly smaller than experimental error. Could microwave power at these low levels stabilize the protein, particularly at high $\mathrm{pH}$ ? The premise is intriguing, but cannot be proven at this time. Based on published reports [33], it was expected that the microwave radiation might enhance the protein's folding rate, but would ultimately destabilize the protein due to non-Joule heating effects. No microwave-dependent destabilization has been observed in our experiments.

Another interesting result is the lower midpoint temperatures determined from network-analyzer peak fits. With the exception of the data at $\mathrm{pH} 2.5, T_{m}$ determined from network-analyzer data is an average of $3.27{ }^{\circ} \mathrm{C}$ lower than that determined from simultaneously obtained UV/VIS absorbance. As evidenced by the sample unfolding at $\mathrm{pH} 4.5$ above, lower $T_{m}$ values from network-analyzer data are a standard result.
TABLE II

VARIATION IN MidPoint TEMPERATURE With PROTEIN CONCENTRATION

\begin{tabular}{cccc}
\hline \hline & & $\mathrm{T}_{\mathrm{m}}\left({ }^{\circ} \mathrm{C}\right)$ \\
RNase A & & \\
Concentration & & UV/VIS with & Return loss \\
& UV/VIS alone & VNA & \\
\hline \hline $680 \mu \mathrm{M}$ & $54.59 \pm 0.50$ & $56.56 \pm 0.50$ & $50.90 \pm 2.16$ \\
$78 \mu \mathrm{M}$ & $53.33 \pm 0.50$ & $54.10 \pm 0.50$ & $51.49 \pm 2.78$ \\
$8.8 \mu \mathrm{M}$ & $52.84 \pm 1.00$ & $53.15 \pm 1.00$ & $56.09 \pm 1.00$ \\
$1.0 \mu \mathrm{M}$ & & & $49.36 \pm 3.32$ \\
$110 \mathrm{nM}$ & & & $54.09 \pm 1.83$ \\
$13 \mathrm{nM}$ & & & $53.44 \pm 4.27$ \\
$1.5 \mathrm{nM}$ & & & $46.66 \pm 3.68$ \\
$170 \mathrm{pM}$ & & & $54.78 \pm 2.01$ \\
$19 \mathrm{pM}$ & & & $59.04 \pm 5.01$ \\
Average & $53.59 \pm 1.00$ & $54.60 \pm 1.76$ & $51.76 \pm 3.08$ \\
\hline \hline
\end{tabular}

UV/VIS absorbance was recorded simultaneously with return loss data at all concentrations, but absorbance was too low for analysis of UV/VIS data below $8.8 \mu \mathrm{M}$. Error in midpoint temperature determined from UV/VIS absorbance at $8.8 \mu \mathrm{M}$ is higher than usual due to low signal.

\section{E. Concentration Series}

A series of unfolding/refolding assays at decreasing concentrations was performed in order to determine the limits of sensitivity of the slot antenna system and to test for evidence of destabilization at low protein concentrations. Protein concentration began at $680 \mu \mathrm{M}$ and was serially decreased to $19 \mathrm{pM}$. Simultaneous UV/VIS and network-analyzer measurements were made at each concentration. A separate UV/VIS absorbance measurement in the absence of microwave power was also made for concentrations above $8.8 \mu \mathrm{M}$. Below $8.8 \mu \mathrm{M}$, UV/VIS absorbance at $288 \mathrm{~nm}$ was lower than experimental error and data could be analyzed.

Midpoint temperatures determined from UV/VIS absorbance and VNA peak fitting at all concentrations are summarized in Table II.

The apparent decrease in midpoint temperature determined from UV/VIS absorbance with decreasing temperature is attributed to the decreasing signal-to-noise ratio at lower protein concentrations. This effect is unlikely to be due to multimerization (formation or unfolding of dimers, trimers, or other higher order structures) since RNase A is a monomer and has been shown to undergo two-state unfolding under these conditions [21], [22], [33]. Protein solutions displayed no evidence of aggregation and unfolding was highly reversible.

Once again, the midpoint temperature derived from UV/VIS absorbance in the presence of microwave radiation exceeds the midpoint temperature determined from UV/VIS absorbance alone by $0.31{ }^{\circ} \mathrm{C}-1.97{ }^{\circ} \mathrm{C}$. For concentrations of $78 \mu \mathrm{M}$ or greater, this temperature difference exceeds the experimental error and may be statistically significant. At $8.8 \mu \mathrm{M}$, the signal strength was so low that $T_{m}$ can only be determined to a precision of approximately $1.0^{\circ} \mathrm{C}$, and the temperature difference may be attributed to experimental error.

Two facts may be gleaned from the concentration-dependent behavior of the midpoint temperature derived from peak fitting. First, $T_{m}$ derived from network-analyzer measurements is again lower than the $T_{m}$ derived from simultaneous UV/VIS 
TABLE III

Minimum PRotein CONCENTRATION FOR POPULAR PROTEIN THERMODYNAMICS TECHNIQUES

\begin{tabular}{ll}
\hline \hline Technique & $\begin{array}{l}\text { Approximate minimum protein } \\
\text { concentration }\end{array}$ \\
\hline \hline UV/VIS absorbance & $\begin{array}{l}\text { Depends on presence of UV- } \\
\text { absorbent residues; } \\
\text { approximately } 120 \mu \mathrm{g} / \mathrm{mL} \text { for } \\
\text { RNase A experiments }\end{array}$ \\
Circular dichroism spectroscopy & $\begin{array}{l}\text { Depends on degree of protein } \\
\text { secondary structure; generally } \\
\text { the same as UV/VIS absorbance }\end{array}$ \\
Differential scanning & $\begin{array}{l}20-30 \mu \mathrm{mL} \\
\text { calorimetry }\end{array}$ \\
& $\begin{array}{l}\text { Depends on presence of } \\
\text { fluorescent residues or groups; } \\
\text { reported as } 10 \mathrm{ng} / \mathrm{mL}(0.8 \mathrm{nM}) \\
\text { for fluorescein-labelled RNase A } \\
{[1]}\end{array}$ \\
Fluorescence spectroscopy & 0.3 ng/mL (19 pM for RNase A) \\
\hline \hline
\end{tabular}

absorbance. The magnitude of this decrease is difficult to gauge due to the difficulty in accurate $T_{m}$ determination at low concentrations. Second, while values of $T_{m}$ determined from network-analyzer measurements showed a wide variation with concentration, from $46.66{ }^{\circ} \mathrm{C}$ to $56.09{ }^{\circ} \mathrm{C}$, no clear concentration-dependent trend was evident. Contrary to expectation, no decrease in stability with at low concentrations was observed. The average midpoint temperature for all concentrations was $51.76^{\circ} \mathrm{C} \pm 3.08{ }^{\circ} \mathrm{C}$.

These concentration dependence studies establish an approximate operating range for the slot antenna system. A wide concentration range (nearly eight orders of magnitude) was used in these experiments. Midpoint temperature could be determined with reasonable accuracy at protein concentrations as low as $19 \mathrm{pM}$; at lower concentrations uncertainty in $T_{m}$ became unacceptably high as the signal strength decreased. The upper concentration limit was not determined in this study, but will probably be limited by protein solubility.

Minimum protein concentrations for several popular techniques for measurement of unfolding/refolding thermodynamics are summarized in Table III. With the exception of fluorescence spectroscopy, all of these techniques require at least $20 \mu \mathrm{g} / \mathrm{mL}$ of protein or greater $(1.5-\mu \mathrm{M}$ RNase A) to obtain good results. Good fluorescent spectroscopy results were obtained at concentrations as low as $0.8 \mathrm{nM}$ of fluorescein-labeled RNase A (approximately $10 \mathrm{ng} / \mathrm{mL}$ ) [1]. This study establishes that thermodynamic data can be obtained from as little as $0.3 \mathrm{ng} / \mathrm{mL}(19 \mathrm{pM})$ of RNase A, more than 40 times lower than the minimum needed for fluorescence spectroscopy.

\section{F. Power Series}

In an attempt to understand the apparent microwave-induced stability increase observed in results from UV/VIS absorbance, a series of unfolding/refolding assays at increasingly low power levels was attempted. If the stability increase was indeed caused by microwave power, then this increase should decrease
TABLE IV

VARIATION IN MidPoint TEMPERATURE WiTH NETWORK ANALYZER POWER

\begin{tabular}{lccc}
\hline \multicolumn{2}{c}{ Test port power } & \multicolumn{2}{c}{ Midpoint temperature $\left({ }^{\circ} \mathrm{C}\right)$} \\
$\mathrm{dB}$ & $\mu \mathrm{W}$ & $\begin{array}{c}\text { UV/VIS with } \\
\text { VNA }\end{array}$ & Return loss \\
\hline \hline 5 & 1780 & $50.77 \pm 0.50$ & $50.54 \pm 2.76$ \\
-5 & 560 & $51.77 \pm 0.50$ & $49.25 \pm 3.04$ \\
-15 & 178 & $51.37 \pm 0.50$ & $56.61 \pm 1.90$ \\
-25 & 56 & $51.17 \pm 0.50$ & $52.38 \pm 1.06$ \\
-35 & 18 & $51.07 \pm 0.50$ & $51.14 \pm 2.56$ \\
& Average & $51.23 \pm 0.37$ & $51.98 \pm 2.82$ \\
\hline \hline
\end{tabular}

TABLE V

BINDING OF FLUORMONE AND ESTRADIOL TO ESTROGEN RECEPTOR $\beta$

\begin{tabular}{lcr}
\hline \hline & \multicolumn{2}{c}{ Dissociation constant $\mathrm{K}_{\mathrm{D}}(\mathrm{nM})$} \\
& Beacon & Return loss \\
\hline \hline Fluormone & $5.71 \pm 0.47$ & $5.40 \pm 2.59$ \\
Estradiol & & $1.60 \pm 0.62$ \\
\hline \hline
\end{tabular}

${ }^{*} \mathrm{~K}_{\mathrm{D}}$ for return loss data reported as average $\mathrm{K}_{\mathrm{D}}$ for all peaks.

or even reverse at sufficiently low power levels. An initial unfolding/refolding UV/VIS absorbance assay was obtained in the absence of microwave power. The results of this assay were used as a baseline against which all other assays were compared. Unfolding/refolding assays were performed at five power levels evenly spaced from -35 to $+5 \mathrm{dBm}$ (from $18 \mu \mathrm{W}$ to $1.78 \mathrm{~mW}$ ). All experiments were performed at a concentration of $0.36 \mathrm{mg} / \mathrm{mL}(26.2 \mu \mathrm{M})$ in a pH 3.5 buffer. Results of the power series are summarized in Table IV.

Midpoint temperature determined from UV/VIS absorbance alone was $50.66{ }^{\circ} \mathrm{C} \pm 0.50{ }^{\circ} \mathrm{C}$. For unknown reasons, this $T_{m}$ is approximately $5{ }^{\circ} \mathrm{C}$ lower than that previously determined. However, midpoint temperatures determined from network-analyzer data were at the expected values.

Stability increase in the presence of microwave power as ascertained from UV/VIS absorbance ranged from $0.11{ }^{\circ} \mathrm{C}$ to $1.11{ }^{\circ} \mathrm{C}$ with an average increase of $0.63{ }^{\circ} \mathrm{C}$. No clear dependence of midpoint temperature on test port power is observed for either UV/VIS or return response data.

\section{G. Ligand Binding Experiments}

Due to the use a long coaxial cable and lack of impedance matching, the return-loss pattern of the scaled-down slot antenna employed for fluorescence polarization experiments displayed a number of peaks in the $10-20-\mathrm{GHz}$ range. A typical return-loss pattern is shown in Fig. 8. In contrast to the return loss of the larger antenna described above (see Fig. 1), peak position varied little. Instead, peak magnitude was sensitive to a number of factors, including temperature, protein concentration, and ligand concentration.

Fig. 9 shows the variation of return-loss magnitude with estrogen receptor $\beta$ (ER- $\beta$ ) concentration for titration of $0.24-\mathrm{nM}$ fluormone with ER- $\beta$ at $25^{\circ} \mathrm{C}$. Return loss is high at low ER- $\beta$ concentration (around $0.1 \mathrm{nM}$ ), decreases in the range from 0.7 to $10 \mathrm{nM}$, then increases with increasing ER- $\beta$ concentration. The first region corresponds to primarily free fluormone and the third region corresponds to primarily bound fluormone, with the inner region representing a mixture of bound and free ligand. 


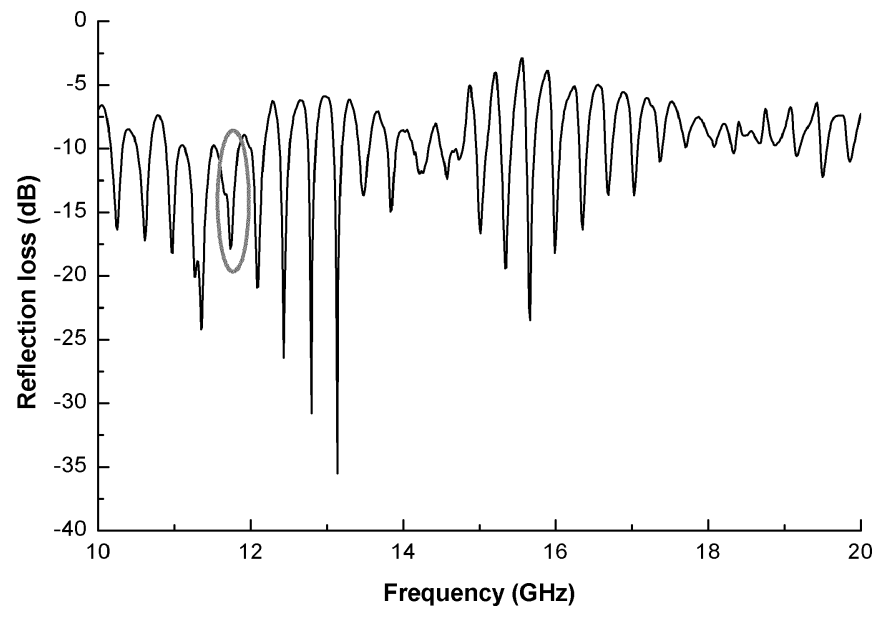

Fig. 8. Representative return loss for scaled slot antenna employed for fluorescence polarization experiments. Sample is 38.8-nM estrogen receptor $\beta$ with $0.24 \mathrm{nM}$ in buffer. The grey circle indicates the peak considered in more detail in Fig. 9.

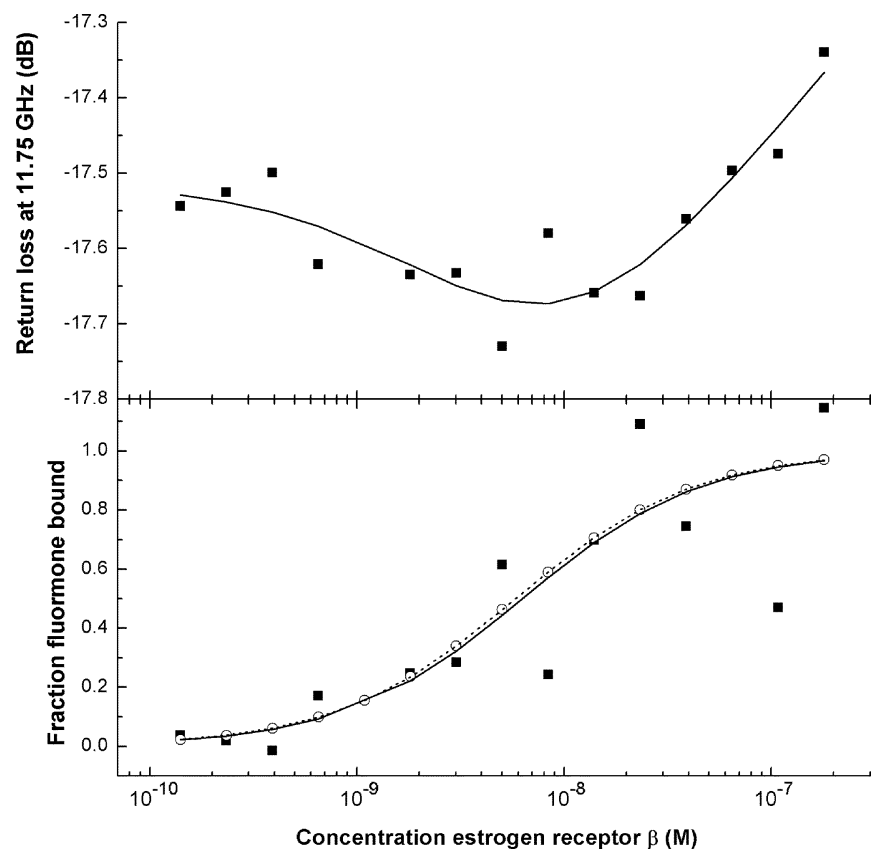

Fig. 9. Variation of return loss at $11.75 \mathrm{GHz}$ with concentration of estrogen receptor. Concentration of fluormone was fixed at $0.24 \mathrm{nM}$. Return-loss data (closed symbols) was fitted to (5) and (6); fits are indicated by solid lines. Fraction ligand bound (open symbols and dashed line) from Beacon data are included in the lower graph. Dissociation constant $K_{D}$ was determined to be $6.17 \pm 4.44 \mathrm{nM}$ for return-loss data and $5.71 \pm \mathrm{nM}$ for Beacon data.

The data fits well to (5) and (6) with dissociation constant $K_{D}$ equal to $6.17 \pm 4.44 \mathrm{nM}$. Several other peaks were identified that yielded good fits to a single-site binding model; values of $K_{D}$ varied from 1.94 to $8.78 \mathrm{nM}$, with average $K_{D} 5.40 \pm$ $2.59 \mathrm{nM}$. Fluorescence data taken simultaneously yielded a $K_{D}$ value of $5.71 \pm 0.47 \mathrm{nM}$. Both of these values compare well to the published dissociation constant $(5.53 \mathrm{nM})$ for a similar fluorescent estradiol [34].

We also performed label-free measurements of the binding of estradiol and ER- $\beta$ using return loss alone. FP data were not recorded for these experiments since no fluorescently ac- tive species were used. As with the fluormone titration experiments, peak position shifted little with concentration, although peak magnitudes varied. Several peaks fitted well to (5) and (6) with $K_{D}$ varying from 1.12 to $2.68 \mathrm{nM}$ and an average $K_{D}$ of $1.60 \pm 0.62 \mathrm{nM}$ (data not shown). The dissociation constant for this system measured by gel filtration analysis was $0.09 \mathrm{nM}$ [25]. Values of dissociation constant $K_{D}$ determined from fluorescence polarization and return-loss measurements are summarized in Table V.

\section{DISCUSSION}

Our coaxial-fed slot antenna has been used successfully for detection of protein conformational changes in the antenna's near zone. We have demonstrated that both larger (unfolding/refolding) and smaller (ligand binding) conformational changes can be monitored. In all cases, similar thermodynamic parameters (for either unfolding/refolding or binding) were obtained with both the slot antenna and conventional optical means.

The combined cuvette/antenna system allows simultaneous measurements of UV/VIS absorbance and return reflection loss, enabling correlation of antenna measurements with an established method. Fitting the return reflection loss to a series of Lorentzian peaks allows examination of the temperature-dependent behavior of individual peaks. Selected peaks, usually 1-2 peaks per return-loss pattern, could be fitted to a two-state unfolding model, and frequency shifts of these peaks appear to correlate with changes in protein conformation. Midpoint temperatures determined from these frequency shifts are comparable to the $T_{m}$ values derived from UV/VIS absorbance, and exhibit similar $\mathrm{pH}$-dependent behavior. Thermodynamic parameters were obtained at concentrations as low as $19 \mathrm{pM}$, far lower than the minimum detectable concentration from UV/VIS absorbance. The midpoint temperature $T_{m}$ measured by UV/VIS absorbance in the absence of microwave power did not decrease when simultaneous UV/VIS and dielectric measurements were performed, implying that the protein is not destabilized by microwave power.

An advantage of this slot antenna approach over other approaches is that proteins need not be labeled or otherwise altered. The titration experiments discussed above in Section III-B demonstrate that any dielectric material, including proteins and nucleic acids, in aqueous solution can be examined by this technique. Position of peaks in the return-loss spectra were shown to vary with calculated permittivity for titration of acetone and methanol into water; data at permittivities below 60 fitted well to the expected inverse square root of the permittivity (see Fig. 2). Peak shifts were large, up to $200 \mathrm{MHz}$, for these experiments because of the large changes in solution permittivity. Peaks were shown to vary linearly with concentration of either RNase or RNA (see Fig. 3). Peak shifts for the biological macromolecule titrations were much smaller than the organic solvents, probably due to the low concentration of macromolecule ( $200 \mu \mathrm{M}$ or less) and the higher water concentration $(55.6 \mathrm{M})$. These results suggest that the antenna resonance responds to nonspecific changes in permittivity, meaning that a resonant slot antenna can be used to observe any activity involving a permittivity change. 
Unfolding/refolding of RNase A was measured at concentrations as low as $19 \mathrm{pM}$. Of the techniques currently used for similar biological studies, only fluorescence spectroscopy can be used to obtain measurements at protein concentrations in the low picomolar to nanomolar range, but this technique requires that most biomolecules be labeled with a fluorescent entity (see Table III). Other common methods such as UV/VIS or circular dichroism spectroscopy require much higher protein concentrations.

Several unresolved issues need to be addressed. First, although midpoint temperature may be ascertained to reasonable accuracy from frequency shifts of network-analyzer peaks, determination of unfolding/refolding enthalpy $\Delta H_{v H}$ has been far less satisfactory. The values of $\Delta H_{v H}$ from network-analyzer peak fitting varied widely among different data sets. In some cases, as in the RNase A unfolding at $\mathrm{pH} 4.5$ above, values of $\Delta H_{v H}$ that are lower than those from UV/VIS absorbance, but still reasonable, were obtained. In most cases, $\Delta H_{v H}$ values from network-analyzer data are small and extremely high in error. These low values of enthalpy are unlikely to be due to protein destabilization since unfolding/refolding enthalpy values from UV/VIS absorbance from this work were very similar to UV/VIS and calorimetric values from the literature (data not shown).

There are two explanations for these small and error-prone enthalpy values. First, accurate enthalpy determination is rendered impossible by error in the native and unfolded baselines. Generally, return response peak frequency shifts correspond to a linear model at temperatures at which the protein is either folded or unfolded, but baseline fitting to network-analyzer data was usually not as accurate as was fitting to UV/VIS absorbance. Uncertainty in baseline determination does not entirely explain this problem since values of $\Delta H_{v H}$ from the baseline-free fitting method were similar in magnitude and error to those obtained from the baseline-dependent method. These errors may be due to a low- $Q$ antenna; improvements in the antenna system may facilitate more accurate determination of $T_{m}$ and $\Delta H_{v H}$.

On the other hand, these values of unfolding or refolding enthalpy may indeed be accurate. Data from UV/VIS absorbance and VNA return loss reflect very different phenomena. UV/VIS absorbance assesses changes in the absorbance of aromatic residues (in this case, tyrosine only, since wild-type or naturally occurring RNase A possesses no tryptophan) and disulfide bonds [35]. Aromatic residues such as tyrosine tend to be located in the hydrophobic core at the protein interior. Of the six tyrosines in RNase A, two (Tyr 76 and 115) are completely solvent exposed; the remaining four are partially or completely buried in the hydrophobic exterior [36]. Dielectric spectroscopy in the observed frequency range focuses on changes in water permittivity, particularly that of bound water [16]. Since RNase A contains no internal water molecules, the waters affected by the microwave radiation must be either on the protein surface or in bulk solution. It is possible that the waters on the protein surface respond to protein unfolding at a lower temperature than do the hydrophobic molecules of the core. Perhaps the entropy of the hydrophilic surface residues increases long before the unfolding of the core, and this is the phenomenon observed by the network-analyzer data. The lower values of $\Delta H_{v H}$ may also be explained if these changes in the entropy of surface residues extend over a wider temperature range than does unfolding of the hydrophobic core. Additional experiments will be necessary to resolve these enthalpy determination issues.

The low levels of microwave power used in these experiments did not destabilize the protein. On the contrary, midpoint temperatures measured by UV/VIS absorbance were higher in the presence of microwave power. Our results support those of Bohr and Bohr [33], in which the folding rate of a protein was enhanced by microwave power at $2.45 \mathrm{GHz}$. If the radiation did not affect the protein's unfolding rate, then the presence of microwave power would, therefore, increase protein stability. This increase was expected to disappear at low power levels, but we observed no power-dependent effects. There are several possible explanations for this negative result. First, the apparent increase of stability with microwave power may not be statistically significant since the magnitude of the increase is approximately the size of the experimental error The power output from the network analyzer may not be sufficiently low to eliminate the stability increase. These experiments were performed over a fairly small power range, only two orders of magnitude. Any change in stability increase over this power range may be smaller than the experimental error. Significantly lower power outputs may be needed to eliminate or reverse the stability increase.

Ligand-binding experiments with estrogen receptor $\beta$ demonstrate that the slot antenna system's usefulness is not limited to unfolding/refolding experiments. It is expected that the same phenomenon is observed by all slot antenna measurements: changes in water permittivity, especially changes due to reorganization of the water shells surrounding proteins or small molecules in solution. Although estrogen receptors, like other nuclear receptors, undergo considerable structural change upon ligand binding [37], this conformational change is not expected to be as large as that associated with protein unfolding/refolding.

The smaller conformational change may be one reason for error in dissociation constant determination. Unlike experiments with larger-scale antennas used for unfolding/refolding experiments, peak positions did not vary, although peak magnitude appeared to reflect conformational changes. Another cause for error was the mechanical instability of the system. As with unfolding/refolding experiments, the coaxial cable feed was highly sensitive to perturbation. In addition, the position of the test tube within the sample holder had a large effect on return loss.

Nonetheless, very similar dissociation constants were obtained from data taken by both fluorescence polarization and by return loss (5.71 $\mathrm{nM}$ versus $5.40 \mathrm{nM}$, respectively). We also demonstrated that the system could be used alone to detect binding events inaccessible to fluorescence polarization by measuring the binding of unlabeled estradiol to the same receptor. Although our value of $K_{D}$ was somewhat larger than that measured by other means $(1.60 \mathrm{nM}$ versus $0.09 \mathrm{nM}$ [34]), it is very promising that our technique can be used to measure quantities previously accessible only through binding of radiolabeled ligands.

Overall, the slot antenna system performed very well. Temperature-dependent changes in RNase A could be measured, and 
thermodynamic parameters from these measurements were similar to those derived from UV/VIS absorbance. Binding of a fluorescent ligand to estrogen receptor $\beta$ was recorded using both fluorescence polarization and return-loss measurement; similar values of the dissociation constant $K_{D}$ were found from both sets of data. Measurement of the binding of unlabeled estradiol was monitored using only return-loss measurements; such measurements cannot be performed using fluorescence polarization. Future designs will include a more mechanically robust and higher $Q$ antenna design. Also, other types of experiments such as enzyme kinetics, chemical denaturation, and ligand binding will be performed.

\section{ACKNOWLEDGMENT}

The authors thank to A. Bettermann, Dr. D. McCaslin, and Dr. C. Paulson, all of the University of Wisconsin-Madison, L. Palmer, Epic Systems, Madison, WI, and Dr. J. Peck, Stanford Research Systems, Sunnyvale, CA.

\section{REFERENCES}

[1] R. L. Abel, M. R. Haigis, C. Park, and R. T. Raines, "Fluorescence assay for the binding of ribonuclease A to the ribonuclease inhibitor protein," Anal. Biochem., vol. 306, pp. 100-107, Jul. 2002.

[2] I. Ermolina, H. Morgan, N. G. Green, J. J. Milner, and Y. Feldman, "Dielectric spectroscopy of tobacco mosaic virus," Biochem. Biophys. Acta, vol. 1622, pp. 57-63, Apr. 2003.

[3] A. Markelz, S. Whitmire, J. Hillebrecht, and R. Birge, "THz time domain spectroscopy of biomolecular conformational modes," Phys. Med. Biol., vol. 47, pp. 3797-3805, Nov. 2002

[4] J. Hefti, A. Pan, and A. Kumar, "Sensitive detection method of dielectric dispersions in aqueous-based, surface-bound macromolecular structures using microwave spectroscopy," Appl. Phys. Lett., vol. 75, pp. 1802-1804, Sep. 1999.

[5] M. Suzuki, J. Shigematsu, and T. Kodama, "Hydration study of proteins in solution by microwave dielectric analysis," J. Phys. Chem., vol. 100, pp. 7279-7282, Apr. 1996.

[6] G. R. Facer, D. A. Notterman, and L. L. Sohn, "Dielectric spectroscopy for bioanalysis: From $40 \mathrm{~Hz}$ to $26.5 \mathrm{GHz}$ in a microfabricated wave guide," Appl. Phys. Lett., vol. 78, pp. 996-998, Feb. 2001.

[7] S. E. Whitmire, D. Woldpert, A. G. Markelz, J. R. Hillebrecht, J. Galan, and R. R. Birge, "Protein flexibility and conformational state: A comparison of collective vibrational modes of wild-type and D96N bacteriorhodopsin," Biophys. J., vol. 85, pp. 1269-1277, Aug. 2003.

[8] Y. D. Feldman and V. D. Fedotov, "Dielectric relaxation, rotational diffusion and the heat denaturation transition in aqueous solutions of RNase A," Chem. Phys. Lett., vol. 143, pp. 309-312, Jan. 1988.

[9] A. Bonincontro, A. De Francesco, and G. Onori, "Temperature-induced conformational changes of native lysozyme in aqueous solution studied by dielectric spectroscopy," Chem. Phys. Lett., vol. 301, pp. 189-192, Feb. 1999.

[10] D. W. van der Weide and K. M. Taylor, "Microwave dielectric spectroscopy method and apparatus," U.S. Patent 6801 029, Oct. 11, 2002.

[11] M. K. Choi, K. Taylor, A. Bettermann, and D. W. van der Weide, "Broadband 10-300 GHz stimulus-response sensing for chemical and biological entities," Phys. Med. Biol., vol. 47, pp. 3777-3787, Nov. 2002.

[12] K. M. Taylor and D. W. van der Weide, "Sensing folding of solution proteins with resonant antennas," presented at the 9th Int. Terahertz Electronics Conf., vol. 9, Charlottesville, VA, 2001.

[13] _ _ "Microwave assay for detecting protein conformation in solution," in Instrumentation for Air Pollution and Global Atmospheric Monitoring, R. L. Spellicy, Ed. Boston, MA: SPIE Press, 2002, vol. 4574, Proceedings of SPIE, pp. 137-143.

[14] S. Bone and B. Zaba, Bioelectronics. Chichester, U.K.: Wiley, 1992.

[15] E. H. Grant, R. J. Sheppard, and G. P. South, Dielectric Behavior of Biological Molecules in Solution. Oxford, U.K.: Oxford Univ. Press, 1978.
[16] R. Pethig, "Protein-water interactions determined by dielectric methods," Annu. Rev. Phys. Chem., vol. 43, pp. 177-205, 1992.

[17] R. H. Henchman and J. A. McCammon, "Structural and dynamic properties of water around acetylcholinesterase," Protein Sci., vol. 11, pp. 2080-2090, Nov. 2002.

[18] V. P. Denisov and B. Halle, "Thermal denaturation of ribonuclease A characterized by water $17 \mathrm{O}$ and $2 \mathrm{H}$ magnetic relaxation dispersion," Biochemistry, vol. 37, pp. 9595-9604, Jun. 1998.

[19] H. G. Akhavan and D. Mirshekar-Syahkal, "Slot antennas for measurement of properties of dielectrics at microwave frequencies," presented at the Nat. Antennas Propagation Conf., 1999.

[20] C. A. Balanis, Antenna Theory: Analysis and Design, 2nd ed. New York: Wiley, 1997.

[21] T. A. Klink, K. J. Woycechowsky, K. M. Taylor, and R. T. Raines, "Contribution of disulfide bonds to the conformational stability and catalytic activity of ribonuclease A," Eur. J. Biochem., vol. 267, pp. 566-572, Jan. 2000.

[22] C. N. Pace, G. R. Grimsley, S. T. Thomas, and G. I. Makhatadze, "Heat capacity change for ribonuclease A folding," Protein Sci., vol. 8, pp. 1500-1504, Jul. 1999.

[23] G. J. Parker, T. L. Law, F. J. Lenoch, and R. E. Bolger, "Development of high throughput screening assays using fluorescence polarization: Nuclear receptor-ligand-binding and kinase/phosphatase assays," $J$. Biomol. Screening, vol. 5, pp. 77-88, 2000.

[24] K. Pettersson and J.-A. Gustafsson, "Role of estrogen receptor beta in estrogen action," Annu. Rev. Physiol., vol. 63, pp. 165-192, 2001.

[25] G. G. J. M. Kuiper, J. G. Lemmen, B. Carlsson, J. C. Corton, S. H. Safe, P. T. van der Saag, B. van der Burg, and J.-A. Gustafsson, "Interaction of estrogenic chemicals and phytoestrogens with estrogen receptor b," Endocrinology, vol. 139, pp. 4252-4263, Oct. 1998.

[26] O. H. Lowry, N. J. Rosebrough, A. L. Farr, and R. J. Randall, "Protein measurement with the Folin phenol reagent," J. Biol. Chem., vol. 193, pp. 265-275, Nov. 1951.

[27] L. A. Marky and K. J. Breslauer, "Calculating thermodynamic data for transitions of any molecularity from equilibrium melting curves," Biopolymers, vol. 26, pp. 1601-1620, Sep. 1987.

[28] D. M. John and K. M. Weeks, "van't Hoff enthalpies without baselines," Protein Sci., vol. 9, pp. 1416-1419, Jul. 2000.

[29] Fluorescence Polarization Technical Resource Guide, 3rd ed., PanVera Corporation, Madison, WI, 2002.

[30] M. Kahrizi, T. K. Sarkar, and Z. A. Maricevic, "Analysis of a wide radiating slot in the ground plane of a microstrip line," IEEE Trans. Microw. Theory Tech., vol. 41, pp. 29-37, Jan. 1993.

[31] R. Pethig, Dielectric and Electronic Properties of Biological Materials. Chichester, U.K.: Wiley, 1979.

[32] M. A. Olson, "Calculations of free-energy contributions to protein-RNA complex stabilization," Biophys J., vol. 81, pp. 1841-1853, Oct. 2001.

[33] H. Bohr and J. Bohr, "Microwave-enhanced folding and denaturation of globular proteins," Phys. Rev. E, Stat. Phys. Plasmas Fluids Relat. Interdiscip. Top., vol. 61, pp. 4310-4314, Apr. 2000.

[34] S. Suzuki, K.-I. Ohno, T. Santa, and K. Imai, "Study on interactions of endocrine disrupters with estrogen receptor-b using fluorescence polarization," Anal. Sci., vol. 19, pp. 1103-1108, Aug. 2003.

[35] S. C. Gill and P. H. von Hippel, "Calculation of protein extinction coefficients from amino acid sequence data," Anal. Biochem, vol. 182, pp. 319-326, Nov. 1989.

[36] M. H. Dung and J. A. Bell, "Structure of crystal form IX of bovine pancreatic ribonuclease A," Acta Cryst., vol. D53, pp. 419-425, Jul. 1997.

[37] D. Moras and H. Gronemeyer, "The nuclear receptor ligand-binding domain: Structure and function," Curr. Op. Cell Biol., vol. 10, pp. 384-391, Jun. 1998.

Kimberly M. Taylor (S'04) received the B.S. degree in physics from the University of Virginia, Charlottesville, in 1994, the M.A. degree in biophysics from The Johns Hopkins University, Baltimore, MD, in 1997, and is currently working toward the Ph.D. degree in biophysics at the University of Wisconsin-Madison.

She was a National Institutes of Health (NIH) Molecular Biophysics Trainee. Her research interests include protein function and thermodynamics and the applications of RF, microwave, and terahertz techniques to problems of biomedical and biochemical interest.

Ms. Taylor was the recipient of a Howard Hughes Predoctoral Fellowship. 


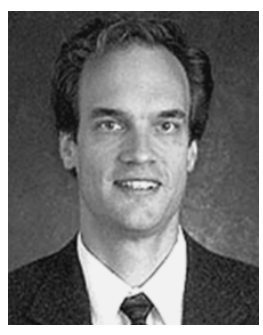

Daniel W. van der Weide (S'86-M'86) received the B.S.E.E. degree from the University of Iowa, Iowa City, in 1987, and the Master's and Ph.D. degrees in electrical engineering from Stanford University, Stanford, CA, in 1989 and 1993, respectively.

He held summer positions with the Lawrence-Livermore National Laboratory and Hewlett-Packard, and full-time positions with Motorola as an Engineer and the Watkins-Johnson Company as a Member of the Technical Staff. From 1993 to 1995, he was a Post-Doctoral Researcher with the Max-Planck-Institut für Festkörperforschung (Solid State Research), Stuttgart, Germany, after which he joined the Department of Electrical and Computer Engineering, University of Delaware, as an Assistant and Associate Professor and Director of the Center for Nanomachined Surfaces. In 1999, he joined the Department of Electrical and Computer Engineering, University of Wisconsin-Madison, as an Associate Professor. From 2002 to 2004, he was a University of Wisconsin Vilas Associate. He was the Principal Investigator on a 2003 Air Force Office of Scientific Research (AFOSR) Multiuniversity Research Initiative (MURI) overseen by Lt. Col. G. Pomrenke entitled, "Nanoprobe Tools for Molecular Spectroscopy and Control." His current research involves ultrafast electronics, one-dimensional (1-D) electron systems, and the application of high-frequency techniques in biotechnology.

Dr. van der Weide was the recipient of the National Science Foundation (NSF) CAREER and PECASE Awards in 1997 and the Office of Naval Research (ONR) Young Investigator Program Award in 1998. 